\title{
Chemokine receptor 7 enhances cell chemotaxis and migration of metastatic squamous cell carcinoma of head and neck through activation of matrix metalloproteinase-9
}

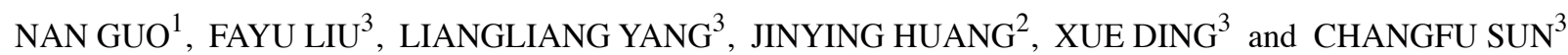 \\ Departments of ${ }^{1}$ Head and Neck Surgery, and ${ }^{2}$ Pathology, Liaoning Cancer Hospital and Institute, Shenyang, \\ Liaoning 110042; ${ }^{3}$ Department of Oromaxillofacial-Head and Neck, Oral Maxillofacial Surgery, \\ School of Stomatology, China Medical University, Shenyang, Liaoning 110002, P.R. China
}

Received March 26, 2014; Accepted May 14, 2014

DOI: $10.3892 /$ or.2014.3242

\begin{abstract}
The mechanisms leading to squamous cell carcinoma of head and neck (SCCHN) metastasis are not fully understood. Although evidence shows that the chemokine receptor 7 (CCR7) and its ligand CCL19 may regulate tumor dissemination, their role is not clearly defined in SCCHN. Matrix metalloproteinases break consisting of tissue barrier to the surrounding tissue invasion and metastasis by destroying the balance of matrix degradation of the basement membrane of tumor cells and extracellular matrix (ECM). We used chemotaxis and migration assays, western blotting, gelatin zymography, actin polymerization assay, immunofluorescence staining and immunohistochemical analysis to explore whether MMP-9 can be activated by CCL19 (CCR7's ligand) and its role in SCCHN. The experiments were performed in the metastatic SCCHN cell line PCI-37B after pre-incubation of the cells with CCL19 and SB-3CT (inhibitor of MMP-9). Our results demonstrated that CCR7 favors PCI-37B cell chemotaxis and migration, upregulation of MMP-9 protein and motivates the activity of MMP-9 protein, induces reorganization of the actin cytoskeleton and upregulation of MMP-9 protein. SB-3CT can block all these effects. Collectively, our data indicated that CCR7 regulates cell chemotaxis and migration via MMP-9 in metastatic SCCHN, and these results provide a basis for new strategies in preventing metastases of SCCHN.
\end{abstract}

Correspondence to: Dr Changfu Sun, Department of Oromaxillofacial-Head and Neck, Oral Maxillofacial Surgery, School of Stomatology, China Medical University, 117 Nanjing Bei Jie, Heping, Shenyang, Liaoning 110002, P.R. China

E-mail: changfusun@hotmail.com

Dr Fayu Liu, Department of Oromaxillofacial-Head and Neck, Oral Maxillofacial Surgery, School of Stomatology, China Medical University, Shenyang, Liaoning 110002, P.R. China

E-mail:1fyhjk@126.com

Key words: CCR7, MMP-9, SCCHN, migration

\section{Introduction}

Squamous cell carcinoma of head and neck (SCCHN), a malignant tumor of epithelial origin, represents $>90 \%$ of all head and neck cancers (1). In SCCHN, the 5-year survival rate is only $30-40 \%$. The mechanisms which lead to the high level of malignancy, particularly metastasis to lymph node and low survival rate, are not completely understood, despite substantial improvements in the diagnosis and local management of, and chemotherapy for, SCCHN (2).

Chemokines are a superfamily of small chemoattractant cytokines that mediate their effects by binding to G-proteincoupled receptors. Chemokines are classified into 4 highly conserved groups: $\mathrm{CXC}, \mathrm{CC}, \mathrm{C}$ and $\mathrm{CX} 3 \mathrm{C}$, based on the position of the first two cysteines adjacent to the amino terminus. The CC chemokine receptor 7 (CCR7) plays a central role in regulating migration of lymphocytes to lymph nodes, such as in mature dendritic cells (DCs) (3), T and B cells (4); flow of calcium ions, changes of cytoskeletal structure, cell cycle and cell metabolism. Since both metastasis and normal migration of leukocytes involve site-directed movement across vascular barriers, non-small cell lung cancer $(5,6)$, gastric $(7)$ and colorectal carcinoma (8) and $\operatorname{SCCHN}(1,2,9,10)$ cells also use chemokine-mediated mechanisms during the metastatic process (11). However, the signaling mechanisms mediated by CCR7 and induced by CCL19 have yet to be elucidated in SCCHN cells.

The matrix metalloproteinases (MMPs) are a family of zinc-dependent proteases that are responsible for proteolytic degradation of specific extracellular matrix (ECM) components (12). MMP-9 is one of them, known as gelatinase or type IV collagenase. They are able to degradate IV collagen, which is associated with invasion and metastasis of tumor. Many researchers report high expression of MMP-9 in several types of migration and invasion cancers, such as SCCHN (13), prostate cancer (14), Hodgkin's lymphoma (15), papillary thyroid carcinoma (16) and brain tumor (17). Thus, MMP-9 is considered the maker of metastasis and invasion of SCCHN to malignant tumor.

Recently, a new role was described for the chemokine family: signaling via chemokine receptors can modulate tumor 
cell expression of MMP-9 which can then facilitate adhesion of cancer cells to and/or invasion through ECM. CCR7induced MMP-9 expression is an important regulatory factor (18). The expression of MMP-9 was enhanced in a variety of malignant tumors, cultured tumor cells and oncogene transformed cells. In vitro migration assay confirmed that the high invasive ability of tumor is associated with the high expression of MMP-9 (19-21).

In the present study, we showed for the first time a direct relationship between CCR7 and MMP-9 in SCCHN cells. We also identified a novel mechanism for CCR7-induced invasion and migration, mediated by regulating MMP-9 in SCCHN.

\section{Materials and methods}

SCC cell lines in the head and neck. Metastatic SCCHN cell line PCI-37B, which strongly expresses CCR7, was supplied by the University of Pittsburgh Cancer Institute, USA. PCI-37B were cultured in Dulbecco's modified Eagle's medium (DMEM; Invitrogen, Carlsbad, CA, USA). DMEM was supplemented with $10 \%$ fetal bovine serum (FBS; Gibco, Carlsbad, CA, USA), $100 \mathrm{U} / \mathrm{ml}$ penicillin $\mathrm{G}$ and $100 \mathrm{U} / \mathrm{ml}$ streptomycin.

Antibodies and reagents. CCL19 and CCR7-specific monoclonal antibody (mouse anti-human CCR7 antibody), MMP-2 and -9, bovine serum albumin (BSA) and fibronectin (FN), were purchased from R\&D Systems (Minneapolis, MN, USA). SB-3CT (the inhibitor of MMP-9), and dimethyl sulfoxide (DMSO) were purchased from Sigma (St. Louis, MO, USA). Matrigel ${ }^{\mathrm{TM}}$ Basement Membrane Matrix was purchased from BD Biosciences Pharmingen (Rockville, MD, USA).

Cell chemotaxis assay. The chemotaxis was assayed in Transwell filter insert chambers $(10-\mu \mathrm{m}$ pore size; Corning Costar) as previously described (25). CCL19 (final density, $500 \mathrm{ng} / \mathrm{ml}$ ) was placed in the lower wells. PCI-37B cells treated with or without SB-3CT (inhibition of MMP-9) and anti-CCR7 $\mathrm{mAb}$ in different concentrations or for different times, at $37^{\circ} \mathrm{C}$ in $5 \% \mathrm{CO}_{2}$, were removed from the culture flasks and added to the upper chamber. After $24 \mathrm{~h}$ at $37^{\circ} \mathrm{C}$, cells on the upper surface of the Transwell membrane were wiped off gently with cotton swabs. The lower surface of the filters was fixed with methanol and stained with hematoxylin. Cells that migrated to the lower surface were counted under a microscope (Nikon TE2000-S Eclipse; Nikon, Tokyo, Japan) at x200 magnification. For each experimental condition, 4-5 wells were analyzed in parallel.

Cell migration assay. The methods were the same as for the chemotaxis assay, the changes are cells were seeded onto the Matrigel-coated filter and incubated in serum-free medium with $500 \mathrm{ng} / \mathrm{ml} \mathrm{CCL19}$ for $36 \mathrm{~h}$. Non-invading cells on the upper side of the filters were removed with a moistened cotton swab. Cells that penetrated the membrane were fixed with ice-cold methanol, stained with $0.5 \%$ crystal violet, photographed and counted under the microscope. To assess cellular migration potential, the protocol described above was used, except that Matrigel was omitted. For each experimental condition, 4-5 wells were analyzed in parallel.
Western blotting. PCI-37B cells were treated with and without the inhibitors SB-3CT and CCR7 mAb, followed by CCL19. Whole cells were harvested in lysis buffer, containing sodium diphosphate, sodium trivanadium oxygen, Tris hydrochloric acid, $1 \%$ Triton $\mathrm{X}-100$, protease and phosphatase inhibitors. Then, lysates were centrifuged at $4^{\circ} \mathrm{C}, 14,000 \mathrm{rpm}$, for $30 \mathrm{~min}$ after sonication for $3 \mathrm{sec}$. Protein concentration of the lysate was determined by Bio-Rad protein assay dye reagent (Bio-Rad Laboratories, Richmond, CA, USA). Proteins were size-fractionated on $10 \%$ sodium dodecyl sulfate-polyacrylamide gel electrophoresis (SDS-PAGE) and transferred to nitrocellulose filters by semi-dry blotting. The filter was blocked in phosphate-buffered saline (PBS) containing 1\% skim milk, $0.1 \%$ Triton X-100, sodium chloride and Tris [Tris (hydroxymethyl) aminomethane] overnight at $4^{\circ} \mathrm{C}$. The membrane was incubated with 1/1,000 diluted rabbit antibody SB-3CT (inhibition of MMP-9) for $30 \mathrm{~min}$ at room temperature, and incubated with horseradish peroxidase-conjugated secondary antibodies (goat anti-rabbit; Sigma). Immune complexes were visualized using enhanced chemiluminescence (ECL; Amersham Pharmacia Biotech, Piscataway, NJ, USA). Quantification of the signals was carried out by scanning densitometry using FluorChem software (version 2.0). $\beta$-actin $(1: 1,000)$ served as the internal control. For each experimental condition, $4-5$ wells were analyzed in parallel.

Actin polymerization assay. PCI-37B cells pretreated with or without CCR7 mAb and MMP-9 inhibitor SB-3CT were fixed, permeabilized and stained with TRITC-labeled phalloidin. Following labeling, the samples were washed three times for $10 \mathrm{~min}$ each in PBS to remove the unincorporated label. F-actin distribution following CCL19 stimulation was evaluated by confocal laser scanning microscope (CLSM Leica SP2, Germany).

Immunohistochemical analysis. Seventy-eight specimens of SCCHN tumors with the adjacent metastatic (or normal) lymph nodes and 30 specimens of normal human oral mucosal tissue were obtained from the Head and Neck Tumor Center, School of Stomatology, China Medical University. All the specimens were obtained with the consent of the patients before surgery and in accordance with the Health Insurance Portability. The classification of SCCHN, including primary tumors (T), regional lymph nodes $(\mathrm{N})$, distant metastasis $(\mathrm{M})$ and stage grouping, was determined according to the rules of the International Union Against Cancer (UICC) for Head and Neck Cancer [tumor-nodemetastasis (TNM) classification, 1997). Immunohistochemical staining used conventional horseradish peroxidase immunohistochemical staining methods. In brief, 5- $\mu \mathrm{m}$ sections of the specimens were deparaffinized and hydrated with $0.6 \% \mathrm{H}_{2} \mathrm{O}_{2}$ in methanol to inhibit endogenous peroxidase, antigen retrieval was performed and then incubated with normal blocking serum for $10 \mathrm{~min}$. Then,the sections were incubated with primary antibodies (1:100):CCR7-specific monoclonal antibody and MMP-9 overnight at $4^{\circ} \mathrm{C}$. Immunodetection was performed using peroxidase labeled secondary antibody (R\&D Systems) and diaminobenzidine for visualization. All sections were counterstained with hematoxylin (Sigma). Negative controls included omission of the primary antibody. The cell morphology was analyzed by microscopy (Nikon Eclipse 80i; Nikon, Tokyo, 
A Western blotting

MMP-2

$\beta$-actin

MMP-9

$\beta$-actin
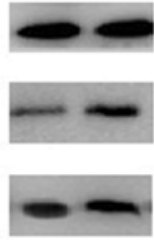

B Gelatin Zymography

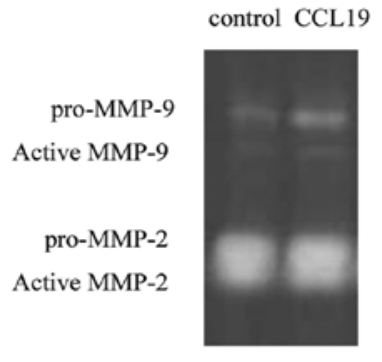

C Western blotting

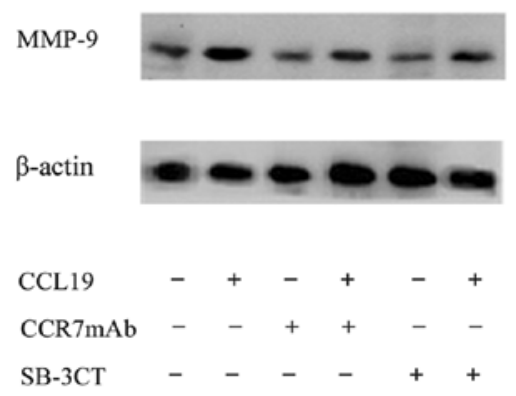

D Gelatin Zymography

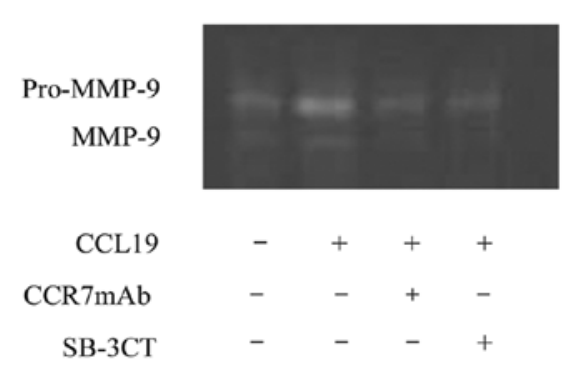

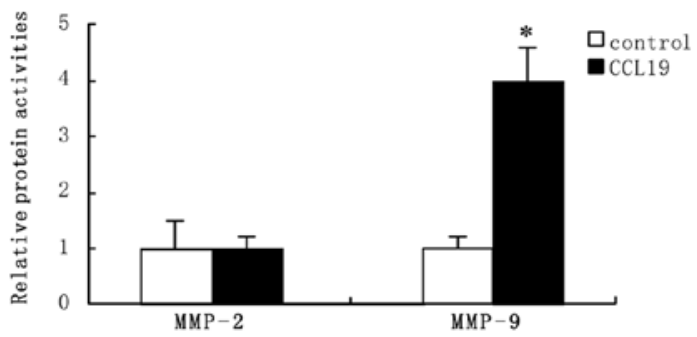
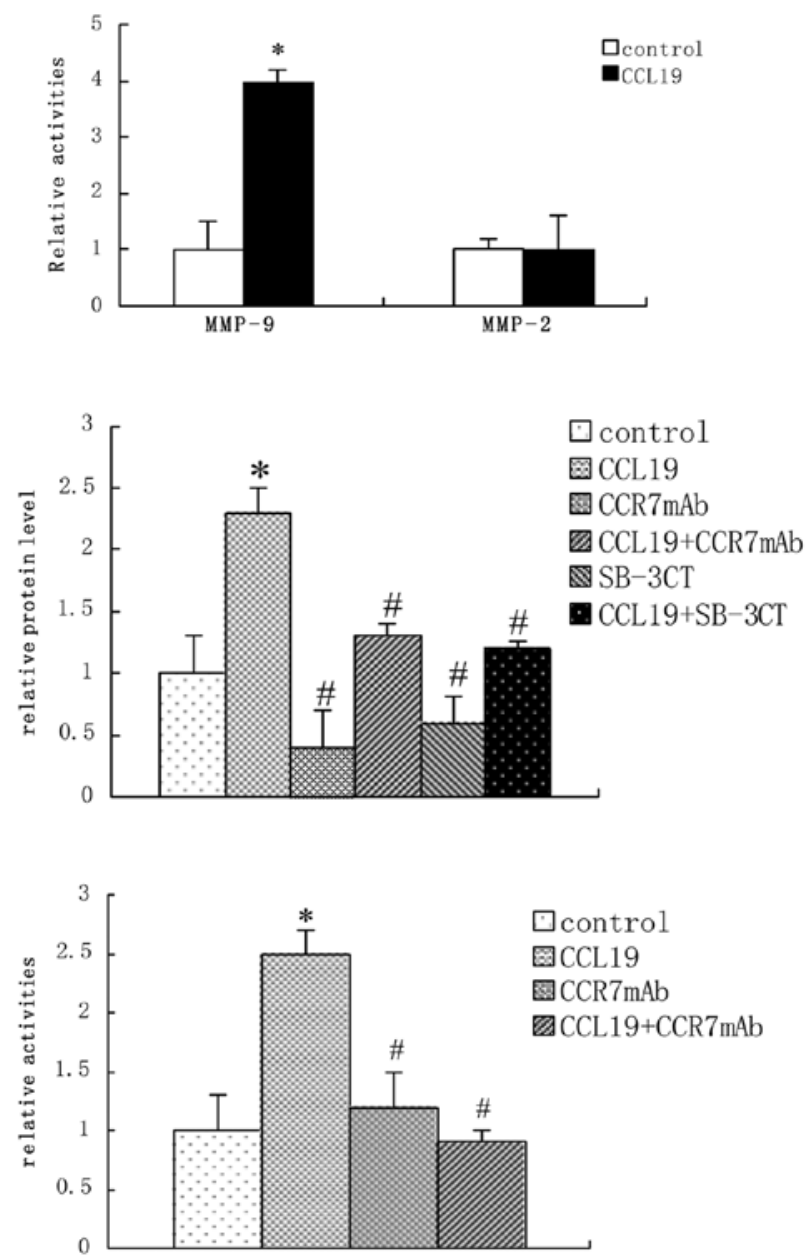

Figure 1. CCL19 induces MMP-9 high expression and enhances its activity. (A) MMP-2 and -9 proteins were analyzed by western blotting. $\beta$-actin was included as loading control. (B) Conditioned media from CCL19-untreated or treated cells were also collected and analyzed for MMP activities by gelatin zymography. (C) PCI-37B cells were treated with and without the MMP-9 inhibitors SB-3CT (10 $\mu \mathrm{mol} / 1)$ for $30 \mathrm{~min}$ and CCR7 mAb $(10 \mu \mathrm{g} / \mathrm{ml})$ for $4 \mathrm{~h}$ at $37^{\circ} \mathrm{C}$, followed by CCL19 $(200 \mathrm{ng} / \mathrm{ml})$ at $37^{\circ} \mathrm{C}$ for $1 \mathrm{~h}$. MMP-9 protein with CCL19, SB-3CT and CCR7 mAb-treated or untreated cells were analyzed by western blotting. $\beta$-actin was included as loading control. (D) MMP activities were collected and analyzed with CCL19, SB-3CT and CCR7 mAb-treated or untreated by gelatin zymography. CCR7 induces MMP-9 expression, which is blocked by CCR7 mAb and MMP-9 inhibitor. The results are representative of three independent experiments. Relative expression to $\beta$-actin is shown as means \pm SD. ${ }^{*} \mathrm{P}<0.05$, compared to the untreated group, ${ }^{"} \mathrm{P}<0.05$, compared to the CCL19 group.

Japan) at x100-400 magnification. According to the percentage of positive tumor cells, all cells were scored as negative $(-,<10 \%$ or no staining); weak positive $(+, 11-50 \%)$; positive $(++, 51-75 \%)$; or strongly positive $(+++,>75 \%)$.

\section{Results}

CCL19 induces MMP-9 high expression and enhances its activity. MMP-2 and -9 are well-documented ECM-degrading enzymes whose activities are associated with SCCHN tumor invasiveness (8). To investigate whether MMP-2 and -9 play a role in the CCL19-stimulated cell invasion, MMP-2 and -9 protein and enzymatic activities were measured by western blotting and gelatin zymography. As shown, the expression and activity of MMP-2 were not significantly altered by CCL19. In contrast to MMP-9, both expression and activity of MMP-9 were found to be markedly elevated after CCL19 treatment (Fig. 1A and B). Thus, we continued researching 
A
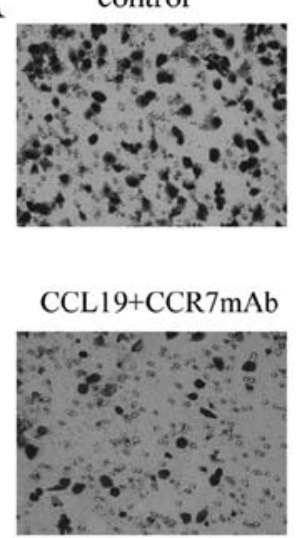

CCL19
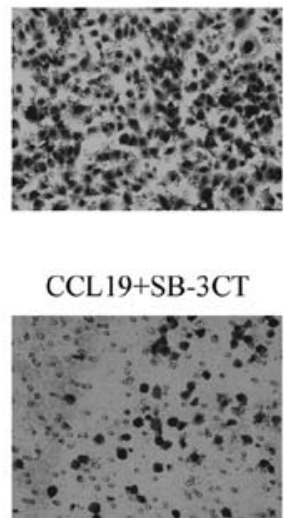

B

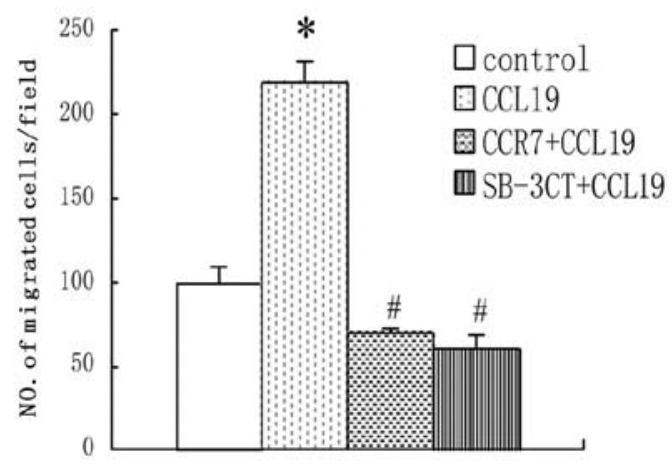

Figure 2. CCL19 induces the migration of PCI-37B cells and SB-3CT blocks it. (A) PCI-37B cells ( $2 \times 10^{5}$ cells/100 $\left.\mu 1\right)$ treated with CCL19 (500 ng/ml for $30 \mathrm{~min})$ and CCR7 $\mathrm{mAb}(10 \mu \mathrm{g} / \mathrm{ml}$ for $4 \mathrm{~h})$ or CCL19 $(500 \mathrm{ng} / \mathrm{ml}$ for $30 \mathrm{~min})$ and SB-3CT (10 $\mu \mathrm{mol} / 1 \mathrm{for} 30 \mathrm{~min})$ compared with CCL19-induced (500 ng/ml for $30 \mathrm{~min}$ ) and control. Cells were counted under a microscope at x200 magnification. (B) Results shown are representative of a series of three independent experiments. " $\mathrm{P}<0.05$, compared to the CCL19 untreated control. SB-3CT and CCR7-mAb blocked migration of PCI-37B. " $\mathrm{P}<0.05$, compared to the CCL19induced group calculated by paired Student's t-test.
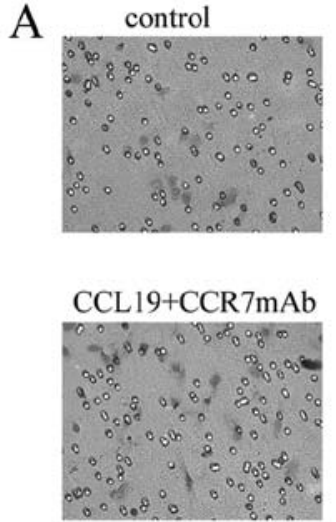
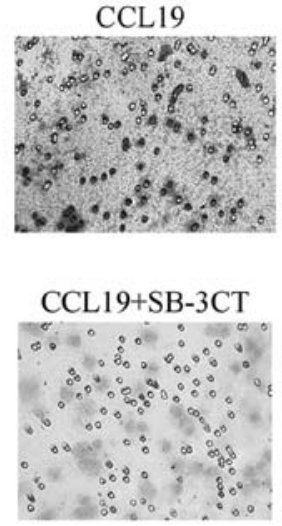

$\mathrm{B}$

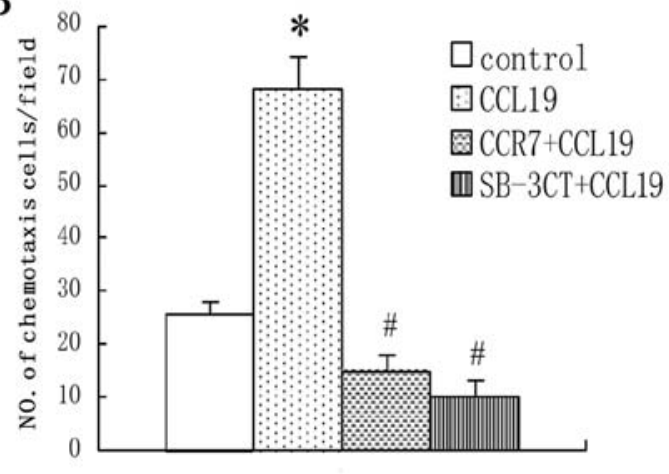

Figure 3. CCL19 activates the chemotaxis ability and SB-3CT abolishes it in PCI-37B. (A) PCI-37B cells ( $2 \times 10^{5}$ cells/100 $\left.\mu 1\right)$ treated with CCL19 (500 ng/ml for $30 \mathrm{~min})$ and CCR7 $\mathrm{mAb}(10 \mu \mathrm{g} / \mathrm{ml}$ for $4 \mathrm{~h})$ or CCL19 $(500 \mathrm{ng} / \mathrm{ml}$ for $30 \mathrm{~min})$ and SB-3CT (10 $\mu \mathrm{mol} / 1$ for $30 \mathrm{~min}) \mathrm{compared} \mathrm{with} \mathrm{CCL19-induced} \mathrm{(500} \mathrm{ng/ml}$ for $30 \mathrm{~min}$ ) and control. Cells were counted under a microscope at $\mathrm{x} 200$ magnification. (B) Results shown are representative of a series of three independent experiments. ${ }^{*} \mathrm{P}<0.05$, compared to the CCL19-untreated control. SB-3CT and CCR7-mAb blocked chemotaxis of PCI-37B. ${ }^{\prime} \mathrm{P}<0.05$, compared to the CCL19induced group calculated by paired Student's t-test.

MMP-9. We found that the expression and activity of MMP-9 were not only elevated after CCL19 treatment but were also diminished after CCR7 mAb treatment, which suggested that this was induced by CCR7 activation. At the same time, the role of CCR7 in MMP-9 activation was also blocked by SB-3CT indicating that CCR7 can activate MMP-9 (Fig. 1C and D). The expression and the activation of MMP-9 were determined by western blot analysis and gelatin zymography, quantified by computer-aided densitometry.

CCL19 induces the migration of PCI-37B cells and SB-3CT blocks it. We treated the cells in the absence or presence of SB-3CT, then conditioned medium of CCL19 was placed on the lower part of a Transwell unit and PCI-37B cells were added to the upper part in the absence or presence of SB-3CT. As shown in Fig. 2, CCL19 significantly enhanced the migration ability of PCI-37B cells that were specifically blocked by the SB-3CT. The inhibitive ability became stronger with the SB-3CT increasing density.
CCL19 activates the chemotaxis ability and SB-3CT abolishes it in PCI-37B. To investigate the correlation between the chemotaxis ability and the activities of CCR7 and MMP-9 in the metastatic SCCHN cell line, we separated the cell line into many teams and analyzed their chemotaxis ability in vitro in response to the respective chemokine ligand CCL19, SB-3CT and CCR7 mAb. These experiments showed that CCL19 enhanced chemotaxis of SCCHN significantly as compared with background control levels established with media alone. The SB-3CT and anti-CCR7 mAb significantly blocked CCL19-induced cell chemotaxis, as shown in Fig. 3.

CCR7 induces F-actin rearrangement. Cell motility involves regulation of the actin cytoskeleton and the actin-severing protein cofilin regulates actin organization. We found that CCR7 activation leads F-actin polymerization and pseudopodia formation. In untreated cells, we observed a scattered distribution of F-actin (Fig. 5). In the cells treated with CCL19, F-actin arrays and pseudopodia were formatted, while these 

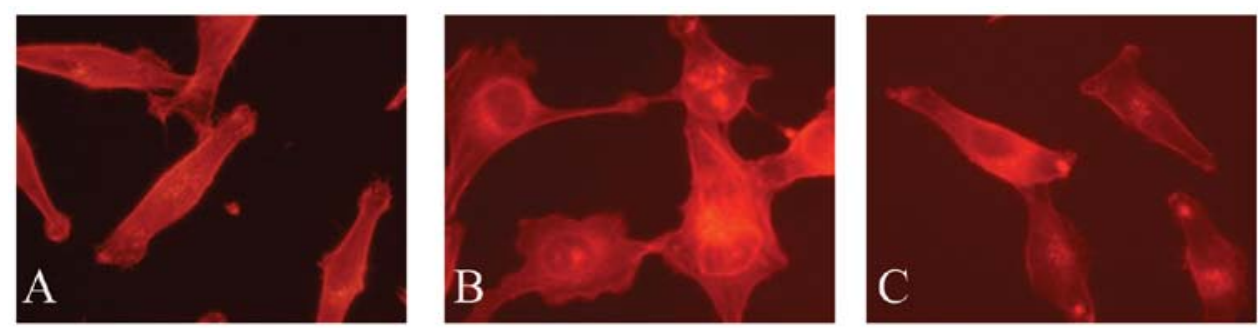

Figure 4. CCL19-induced and SB-3CT blocked reorganization of the actin cytoskeleton of PCI-37B cells. PCI-37B cells were untreated (A), treated with CCL19 $(500 \mathrm{ng} / \mathrm{ml}$, for $30 \mathrm{~min})(\mathrm{B})$, or treated with SB-3CT(10 $\mu \mathrm{M} / 1$, for $30 \mathrm{~min})$ followed by CCL19 $(500 \mathrm{ng} / \mathrm{ml}$ for $30 \mathrm{~min})(\mathrm{C})$. The cells were stained by Rhodamine-labeled phalloidin.

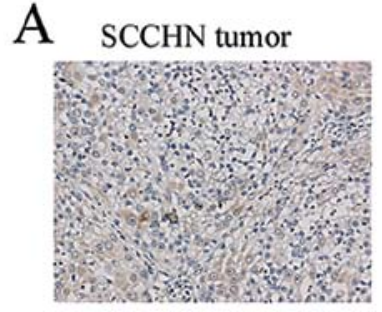

B

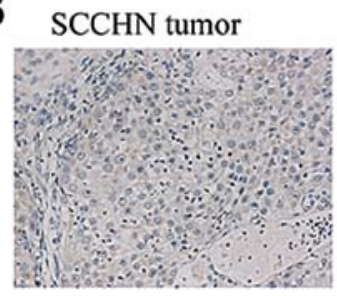

Normal oral musocal

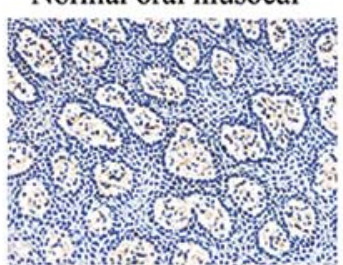

CCR7 immunohistochemical staining

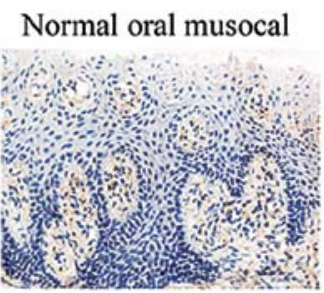

MMP-9 immunohistochemical staining
Metastatic lymph node

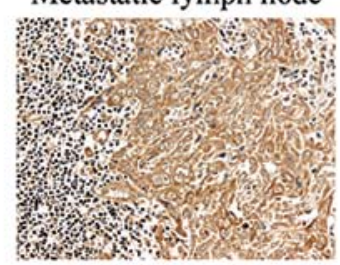

Metastatic lymph node
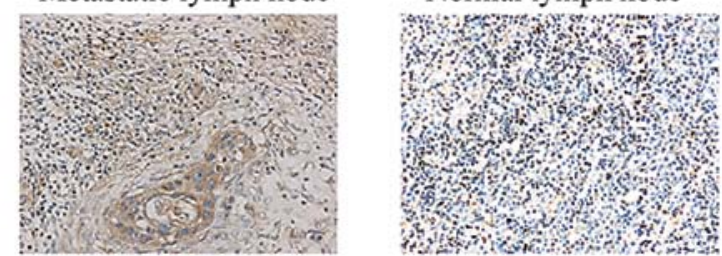

Normal lymph node

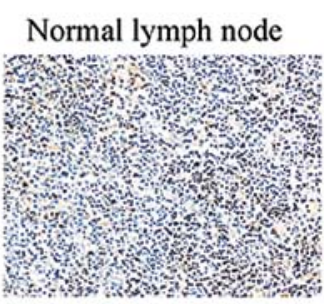

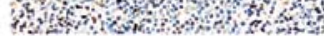

Figure 5. Immunohistochemical staining shows CCR7 and MMP-9 with significant positive correlation in tumor tissues and metastatic lymph nodes. SCCHN tumor tissues (original magnification, x200), metastatic lymph nodes (original magnification, x200), normal lymph nodes (original magnification, x200), and normal human oral mucosal tissues (original magnification, x200) show immunoreactivity for CCR7 (A) and MMP-9 (B). CCR7 immunoreactivity was observed mainly in the cell membrane and cytoplasm of tumor cells, conforming with MMP-9 immunoreactivity. CCR7 and MMP-9 expressed in normal lymph nodes and normal human oral mucosal tissues were weak or absent.

effects were blocked by SB-3CT. We therefore consider that the actin cytoskeletal rearrangement induced by CCL19 requires MMP-9.

CCR7 and MMP-9 expressed by immunohistochemical staining have significant positive correlation in tumor tissues and metastatic lymph nodes. Using immunohistochemistry, we investigated the location of CCR7 and MMP-9 in SCCHN tumor tissues, metastatic lymph nodes, normal lymph nodes and oral mucosal tissues. CCR7 and MMP-9 were found in the cell membrane and cytoplasm, mainly expressed in the surrounding of stroma in tumor cells and metastatic lymph node cells. Analyzing the sections of CCR7 and MMP-9 staining in normal lymph nodes and oral mucosal tissues, we observed that the number of stained cells was low and that they were not expressed (Fig. 5 and Table I). The expression levels of CCR7 and MMP-9 were both significantly correlated with cervical lymph node metastasis and SCCHN clinical stage $(\mathrm{P}<0.05)$. In addition, the $\mathrm{T} 3 / \mathrm{T} 4$ tumor size also appeared to express high levels of MMP-9 $(\mathrm{P}<0.05)$. However, there were no significant differences between CCR7 or MMP-9 expression and age or gender $(\mathrm{P}>0.05)$. A moderate correlation was observed between CCR7 and MMP-9 expression in SCCHN tumor tissues $(\mathrm{P}<0.05)$ and metastatic lymph nodes $(\mathrm{P}<0.05)$, but there was no significant correlation between normal lymph nodes $(\mathrm{P}>0.05)$ and normal oral mucosal tissues $(\mathrm{P}>0.05)$.

\section{Discussion}

CCR7 has been shown to interact with chemokines (CCL19, CCL21) and to modulate tumor cell migration, invasion and proliferation of metastatic squamous cell carcinoma of the head and neck (SCCHN) $(9,10,24)$. However, the mechanisms of chemotaxis and migration and the signaling pathway involved remain poorly understood. We demonstrated that CCR7 regulates cell chemotaxis and migration via MMP-9 in metastatic SCCHN.

Remodeling of the extracellular matrix (ECM), which occurs during many physiological and pathological processes, is one of the requisite events of cellular invasion. MMPs can degrade almost all ECM proteins in the destruction of tumor cell invasion (12). MMP-9 is a well-documented ECM-degrading enzyme whose activities are associated with SCCHN tumor invasion (26). Regulating the activity of MMP-9 modulates 
Table I. Correlations between MMP-9 expression and clinicopathological factors of SCCHN.

\begin{tabular}{|c|c|c|c|c|c|c|c|}
\hline \multirow{2}{*}{$\begin{array}{l}\text { Clinicopathological } \\
\text { characteristics }\end{array}$} & \multirow{2}{*}{$\begin{array}{l}\text { No. of } \\
\text { cases }\end{array}$} & \multicolumn{2}{|c|}{ CCR7 } & \multirow{2}{*}{$\begin{array}{l}\text { Statistical } \\
\text { analysis }\end{array}$} & \multicolumn{2}{|c|}{ MMP-9 } & \multirow{2}{*}{$\begin{array}{l}\text { Statistical } \\
\text { analysis }\end{array}$} \\
\hline & & +-+++ & - & & +-+++ & - & \\
\hline \multicolumn{8}{|l|}{ Age (years) } \\
\hline$\geq 60$ & 40 & 28 & 12 & \multirow[t]{2}{*}{$\chi^{2}=0.023$} & 21 & 19 & \multirow[t]{2}{*}{$\chi^{2}=0.060$} \\
\hline$<60$ & 38 & 26 & 12 & & 21 & 17 & \\
\hline \multicolumn{8}{|l|}{ Gender } \\
\hline Male & 50 & 31 & 19 & \multirow[t]{2}{*}{$\chi^{2}=0.177$} & 30 & 20 & \multirow[t]{2}{*}{$\chi^{2}=1.336$} \\
\hline Female & 28 & 16 & 12 & & 13 & 15 & \\
\hline \multicolumn{8}{|l|}{ Tumor size } \\
\hline $\mathrm{T} 1, \mathrm{~T} 2$ & 64 & 37 & 27 & \multirow[t]{2}{*}{$\chi^{2}=2.091$} & 22 & 42 & \multirow[t]{2}{*}{$\chi^{2}=6.519^{\mathrm{a}}$} \\
\hline $\mathrm{T} 3, \mathrm{~T} 4$ & 14 & 11 & 3 & & 10 & 4 & \\
\hline \multicolumn{8}{|l|}{ Clinical stage } \\
\hline $\mathrm{I}, \mathrm{II}$ & 37 & 15 & 22 & \multirow[t]{2}{*}{$\chi^{2}=13.113^{\mathrm{a}}$} & 9 & 28 & \multirow[t]{2}{*}{$\chi^{2}=18.562^{\mathrm{a}}$} \\
\hline III, IV & 41 & 33 & 8 & & 30 & 11 & \\
\hline \multicolumn{8}{|l|}{ Nodal metastasis } \\
\hline Yes & 36 & 28 & 8 & \multirow[t]{2}{*}{$\chi^{2}=9.770^{\mathrm{a}}$} & 19 & 17 & \multirow[t]{2}{*}{$\chi^{2}=11.375^{\mathrm{a}}$} \\
\hline No & 42 & 18 & 24 & & 7 & 35 & \\
\hline
\end{tabular}

${ }^{\mathrm{a}} \mathrm{P}<0.05$, the internal difference of CCR7 or MMP-9 expression within clinicopathological characteristics.

the degradation of the ECM components which in turn alter cellular invasion, expression and activation.

It has been reported that CCR7 can regulate MMP-9 in lung cancer cells, thus affecting the expression of tumor (18). Chemokine CXCL12, through its specific receptor CXCR4, induced colon cancer metastasis of HT-29 cells by secretion of MMP-9 (22). The interaction of CCL21/CCR7 enhances the expression and secretion of MMP-9 in colon cancer, degradation of ECM and basement membrane, thus promoting invasion and metastasis of colon cancer (23). We speculated that CCR7induced MMP-9 expression is an important regulatory factor.

In the present study, our results (Fig. 1) showed that stimulation of CCL19 could also result in increased expression of MMP-9 in western blot analysis, and the activity in gelatin zymography. Furthermore, we used Transwell chemotaxis and migration assays to examine CCL19-induced activation of MMP-9 that significantly enhanced the chemotaxis (Fig. 3) and migration (Fig. 2) index in SCCHN, and was blocked by MMP-9 inhibitor SB-3CT, thus supporting the hypothesis that CCL19 concentrations in the lymph nodes probably induce SCCHN cell migration into these organs through a CCR7-mediated mechanism. High levels of actin polymerization are required for the formation of pseudopodia, which are needed for chemokine mediated cell migration and invasion into surrounding tissues and efficient metastasis formation (27). In the present study (Fig. 4), we examined TRITC-labeled phalloidin staining by inverted microscope, and observed reorganization of the actin cytoskeleton of PCI-37B was enhanced in response to CCL19, and this function was inhibited by SB-3CT. Immunohistochemical studies confirmed the presence of CCR7 and MMP-9 in the cytoplasm and cell membrane of SCCHN tumor tissues, metastatic lymph nodes, and all significantly correlated with cervical lymph node metastasis and clinical stage, but in normal lymph nodes and oral mucosal tissues they were low or absent.

CCR7 has been reported to be a novel prediction biomarker of metastasis in cancer. Our results showed that stimulation of CCL19 could also result in increased chemotaxis and migration of SCCHN cells. CCR7 induced the activation of MMP-9, and MMP-9 interacted with its counterpart molecules. As has previously been reported, we found that when MMP-9 was inhibited, the CCL19-induced chemotaxis and migration of SCCHN cells were also inhibited.

Future studies including the immunohistochemical analysis of both CCR7 and MMP-9 may be useful for predicting lymph node metastasis (23). Therefore, we suggest that CCR7 activation by CCL19 via MMP-9 may promote SCCHN cell chemotaxis, migration.

In summary, our findings emphasize the potential role of overexpression of the CCR7 in promoting cellular migration and matrix-degrading activities through MMP-9 in SCCHN cells. This information provides a mechanistic rationale for the observed MMP-9 overexpression in advanced-stage SCCHN. To our knowledge, the chemotaxis and migration of SCCHN are very complex systems. It is therefore impossible to cure the tumor by blocking only this pathway. However, it provides us with a novel idea for enhancing the invasiveness of SCCHN and may contribute to the development of improved and more specific therapeutics for the treatment of SCCHN.

\section{Acknowledgements}

The authors acknowledge the University of Pittsburgh Cancer Institute, USA, for supplying the cell line PCI-37B. This study 
was supported by a grant from the National Natural Science Foundation of China (no. 30672331), the Foundation of Education Bureau of Liaoning Province, China (no. 2009A755) and the National Science Foundation for Young Scholars of China (no. 81102058).

\section{References}

1. Yoon Y, Liang Z, Zhang X, Choe M, Zhu A, Cho HT, Shin DM, Goodman MM, Chen ZG and Shim H: CXC chemokine receptor-4 antagonist blocks both growth of primary tumor and metastasis of head and neck cancer in xenograft mouse models. Cancer Res 67: 7518-7524, 2007.

2. Younes MN, Yigitbasi OG, Yazici YD, Jasser SA, Bucana CD, El-Naggar AK, Mills GB and Myers JN: Effects of the integrinlinked kinase inhibitor QLT0267 on squamous cell carcinoma of the head and neck. Arch Otolaryngol Head Neck Surg 133: 15-23, 2007.

3. Yanagawa $\mathrm{Y}$ and Onoé K: CCL19 induces rapid dendritic extension of murine dendritic cells. Blood 100: 1948-1956, 2002

4. Nagira M, Imai T, Yoshida R, Takagi S, Iwasaki M, Baba M, Tabira Y, Akagi J, Nomiyama $\mathrm{H}$ and Yoshie O: A lymphocytespecific CC chemokine, secondary lymphoid tissue chemokine (SLC), is a highly efficient chemoattractant for B cells and activated T cells. Eur J Immunol 28: 1516-1523, 1998.

5. Takanami I: Overexpression of CCR7 mRNA in nonsmall cell lung cancer: correlation with lymph node metastasis. Int J Cancer 105: 186-189, 2003.

6. Zlotnik A: Chemokines and cancer. Int J Cancer 119: 2026-2029, 2006.

7. Arigami T, Natsugoe $S$, Uenosono $Y$, Yanagita $S$, Arima $H$, Hirata M, Ishigami S and Aikou T: CCR7 and CXCR4 expression predicts lymph node status including micrometastasis in gastric cancer. Int J Oncol 35: 19-24, 2009.

8. Günther K, Leier J, Henning G, Dimmler A, Weissbach R, Hohenberger $\mathrm{W}$ and Förster R: Prediction of lymph node metastasis in colorectal carcinoma by expression of chemokine receptor CCR7. Int J Cancer 116: 726-733, 2005

9. Liu FY, Zhao ZJ, Li P, Ding X, Zong ZH and Sun CF: Mammalian target of rapamycin (mTOR) is involved in the survival of cells mediated by chemokine receptor 7 through PI3K/Akt in metastatic squamous cell carcinoma of the head and neck. Br J Oral Maxillofac Surg 48: 291-296, 2010.

10. Zhao ZJ, Liu FY and Sun CF: Effect of chemokine receptor 7 small interfering RNA on proliferation and invasion of squamous cell carcinoma of head and neck. Zhonghua Kou Qiang Yi Xue Za Zhi 44: 5-10, 2009 (In Chinese).

11. Müller A, Homey B, Soto H, Ge N, Catron D, Buchanan ME, McClanahan T, Murphy E, Yuan W, Wagner SN, Barrera JL, Mohar A, Verástegui E and Zlotnik A: Involvement of chemokine receptors in breast cancer metastasis. Nature 410: 50-56, 2001.

12. Corcoran ML,HewittRE,Kleiner DE Jrand Stetler-Stevenson WG: MMP-2: expression, activation and inhibition. Enzyme Protein 49 7-19, 1996.
13. Hong SD, Hong SP, Lee JI and Lim CY: Expression of matrix metalloproteinase-2 and -9 in oral squamous cell carcinomas with regard to the metastatic potential. Oral Oncol 36: 207-216, 2000.

14. Du B, Wang P, Juo X and Du B: Expression of membrane type 1-matrix metalloproteinase in laryngeal carcinoma. Pathol Oncol Res 5: 214-219, 1999.

15. Flavell JR, Baumforth KR, Williams DM, et al: Expression of the matrix metalloproteinase 9 in Hodgkin's disease is independent of EBV status. Mol Pathol 53: 145-149, 2000.

16. Maruyama S, Kawata R, Shimada T, et al: Study of matrix metalloproteinase-2 and -9 in thyroid papillary cancer. Nihon Jibiinkoka Gakkai Kaiho 103: 499-505, 2000 (In Japanese).

17. Jäälinojä J, Herva R, Korpela M, et al: Matrix metalloproteinase 2 (MMP-2) immunoreactive protein is associated with poor grade and survival in brain neoplasms. J Neurooncol 46: 81-90, 2000.

18. Li Y, Liu W, Fang L, Nan J, Zhang Z and Zhou Q: Chemokine receptor 7 induces metastasis of NSCLC via upregulating MMP-9 expression. Zhongguo Fei Ai Za Zhi 13: 1016-1020, 2010 (In Chinese).

19. Sato $\mathrm{H}$ and Seiki M: Regulatory mechanism of $92 \mathrm{kDa}$ type IV collagenase gene expression which is associated with invasiveness of tumor cells. Oncogene 8: 395-405, 1993.

20. Strup-Perrot C, Vozenin-Brotons MC, Vandamme M, et al: Expression and activation of MMP $-2,-3,-9,-14$ are induced in rat colon after abdominal X-irradiation. Scand J Gastroenterol 41: 60-70, 2006.

21. Ogata Y, Matono K, Nakajima M, et al: Efficacy of the MMP inhibitor MMI270 against lung metastasis following removal of orthotopically transplanted human colon cancer in rat. Int J Cancer 118: 215-221, 2006.

22. Brand S, Dambacher J, Beigel F, et al: CXCR4 and CXCL12 are inversely expressed in colorectal cancer cells and modulate cancer cell migration, invasion and MMP-9 activation. Exp Cell Res 310: 117-130, 2005.

23. Sun RH, Wang GB, Li J and Cui J: Role of CCL21/CCR7 in invasion of colorectal carcinoma cell line SW480. Ai Zheng 28: 708-713, 2009 (In Chinese).

24. Wang J,Zhang X, Thomas SM, Grandis JR, Wells A, Chen ZG and Ferris RL: Chemokine receptor 7 activates phosphoinositide-3 kinase-mediated invasive and prosurvival pathways in head and neck cancer cells independent of EGFR. Oncogene 24: 5897-5904, 2005

25. Zhou HY, Wan KF, Ip CK, Wong CK, Mak NK, Lo KW and Wong AS: Hepatocyte growth factor enhances proteolysis and invasiveness of human nasopharyngeal cancer cells through activation of PI3K and JNK. FEBS Lett 582: 3415-3422, 2008.

26. Kurahara S, Shinohara M, lkebe T, et al: Expression of MMPS, MT-MMP, and TIMPs in squamous cell carcinoma of the oral cavity: correlations with tumor invasion and metastasis. Head Neck 21: 627-638, 1999.

27. Li P, Zhao ZJ, Liu FY, Sun LY, Ding X, Zhang WZ, Shang DH and Sun CF: The chemokine receptor 7 regulates cell adhesion and migration via $\beta 1$ integrin in metastatic squamous cell carcinoma of the head and neck. Oncol Rep 24: 989-995, 2010. 